\title{
Antifertility effects of some sulphonamides and related compounds and their accumulation in the epididymides of male rats
}

\author{
P. Y. D. Wong, S. K. D. Lau and W. O. Fu \\ Department of Physiology, University of Hong Kong, Sassoon Road, Hong Kong
}

\begin{abstract}
Summary. Nineteen sulphonamides and related drugs were screened for their antifertility effects in male rats. They were suspended in corn oil and fed orally to rats at 10 times the human dose for a period of 6 months. Of the 19 compounds tested, sulphamethazine, sulphapyridine, dapsone, sulphamethoxypyridazine, sulphaguanidine, sulphathizole, sulphamerazine and sulphadimethoxine reduced fecundity of male rats to $34 \cdot 3,37 \cdot 6$, $38 \cdot 3,53 \cdot 6,55 \cdot 6,58,75$ and $78 \cdot 6 \%$ of control, respectively. The fall in fecundity was due to a reduction in the number of embryos compared with the number of corpora lutea per pregnant female, and, in some cases, was associated with a fall in epididymal sperm concentration and motility. Some of these compounds accumulated in the cauda epididymidis at concentrations equal to or higher than the free drug concentrations in the blood. It is proposed that the antifertility effects of some of these compounds may in part be mediated through a direct effect on epididymal stored spermatozoa, hence compromising some processes vital for fertilization.
\end{abstract}

\section{Introduction}

Although sulphasalazine has been used for a long time to control inflammatory bowel diseases (Svartz, 1942; Dissanayake \& Truelove, 1973), it was only recently realized that it also has an antifertility effect in men. Infertility is associated with a decrease in sperm count and motility and an increased number of abnormal sperm forms (Levi et al., 1979; Toth, 1979). The antifertility effect is reversible and is reproducible in experimental animals (Levi et al., 1982; Pholpramool \& Srikhao, 1983; O'Morain et al., 1985). Sulphasalazine undergoes azo reduction to 5-aminosalicyclic acid and sulphapyridine in the gut (Peppercorn \& Goldman, 1972). The latter appears to be responsible for the antifertility effect of sulphasalazine (Toovey et al., 1981; O'Morain et al., 1984). In the rat, sulphasalazine and sulphapyridine treatment do not affect hormone profile, testis weight and histology, or sperm concentration in the epididymis (Pholpramool \& Srikhao, 1983; O'Morain et al., 1984). These, together with the rapid onset of action and recovery after drug withdrawal indicate that the site of action is the epididymis. However, epididymal functions appeared not to be altered after sulphasalazine treatment (Chodorge et al., 1986).

In this work we have studied the effects of 19 compounds (including sulphapyridine) on the fertility and fecundity of male rats. Their effects on the viability of epididymal spermatozoa and their penetration into the epididymis were also studied.

\section{Materials and Methods}

Animals. Sprague-Dawley rats were obtained from the Laboratory Animal Unit of the University of Hong Kong. They were reared and maintained under SPF conditions at an ambient temperature of $20 \pm 1^{\circ} \mathrm{C}$ and a relative humidity of $60-80 \%$. 
Drug treatment. Nineteen compounds were studied in 5 consecutive fertility trials each consisting of 3 or 4 test compounds over a period of 12 months (Table 1). Each test compound was freshly suspended in corn oil and was fed via gastric intubation into a group of 6-12 male rats weighing about $300 \mathrm{~g}$ at the start of the treatment. The dosage used was 10 times the human dose (Table 1) and treatment was for 6 weeks. Each trial also contained a group of $6-12$ control rats to which corn oil only was fed. The body weight of each rat was taken before each feeding.

Fertility and fecundity measurement. The fertility of the male rats treated with the test compounds was assessed by natural mating. Starting from the 33rd day of feeding, each male rat was sequentially paired with 2 female rats. The second rat was introduced only after mating with the first female was confirmed. Successful mating was verified on the second day by the presence of a dislodged copulatory plug, or, if absent, the presence of spermatozoa in the vaginal smear. The day on which mating occurred was designated Day 1 of pregnancy and the female rats were separated from the males once mating had been confirmed.

On Day 21 of gestation, the females were killed to determine the following values: (1) percentage of pregnant females in each group, (2) mean live embryo number per pregnant female, (3) mean resorbed embryo number per pregnancy, (4) mean number of corpora lutea of pregnancy, and (5) mean embryo crown-rump length.

The fecundity of each test group was represented by the 'Fecundity Index' which was calculated by: mean embryo number/mean corpus luteum number $\times$ Day 21 embryo length $\times \%$ pregnant females. In the earlier trial (Trial I) (Table 1), 'Fecundity Index' was expressed as the 'Embryo Score' which was calculated as the product of the embryo number per pregnant female and the mean Day 21 embryo length.

Collection of epididymal fluids. On the 43rd day of feeding, the male rats were anaesthetized with pentobarbitone sodium ( $60 \mathrm{mg} / \mathrm{kg}$, i.p. injection: Sagatal, May \& Baker Ltd, Dagenham, Essex, U.K.). The contents from both epididymides were collected after cannulation of the epididymal duct and the vas (Wong \& Lee, 1982). Paraffin oil was infused into the lumen of the epididymis using a Harvard infusion pump, displacing the contents into a calibrated polythene tubing (Portex $800 / 100 / 260 / 100$; i.d. $0.86 \mathrm{~mm}$ ) inserted into the vas.

Sperm motility assessment. A small portion of the epididymal content (about $1 \mu \mathrm{l}$ in $2 \mathrm{~mm}$ length of tubing) was suspended in $3 \mathrm{ml}$ oxygenated medium (Wong et al., 1981) containing (mM): $\mathrm{NaCl}, 138 ; \mathrm{KCl}, 4 \cdot 7 ; \mathrm{CaCl}_{2}, 2 \cdot 56, \mathrm{MgSO}_{4}$, $1 \cdot 13$; Tris (pH 7.2), 5; BSA, $0.2 \%$; and glucose, $0.2 \%$. The solution had a calculated osmolarity of $295 \mathrm{mosmol} / 1$. The spermatozoa were incubated in this solution at $34^{\circ} \mathrm{C}$ for $1 \mathrm{~min}$, after which $40 \mu \mathrm{l}$ of the suspension was spread onto a prewarmed glass slide and covered with a prewarmed cover-slip and observed under a microscope $(\times 100$ magnification) equipped with dark-field illumination. In the earlier experiments, sperm motility was assessed visually, but in most experiments motility was measured objectively using time-lapse photography. Three random fields were photographed (ASA 400, exposure time $1 \mathrm{sec}$ ). The forward velocity was determined by analysis from the projected images of the negatives the vector distance of the progressing spermatozoa, with the aid of a digitizer and an IBM personal computer. 'Forward Motility Index' was calculated from the mean velocity $(\mu \mathrm{m} / \mathrm{sec}) \times \%$ motile spermatozoa (Wong et al., 1981).

Determination of sperm concentration in the epididymis. The polythene tubing containing oil and epididymal content was sealed at one end and subjected to centrifugation at $10000 \mathrm{~g}$ for $60 \mathrm{~min}$. The volume of the epididymal content (spermatozoa plus epididymal plasma) flushed out from each cauda was noted. A 10-mm length of the packed sperm pellet (volume 5-6 $\mu \mathrm{l}$ ) was suspended in saline, diluted to the appropriate density and counted by means of a haemocytometer. The original sperm concentration in the intact cauda epididymidis was calculated.

The testes, seminal vesicles and epididymides were weighed and expressed in $\mathrm{g} / 100 \mathrm{~g}$ body weight.

Efferent duct ligation. In one set of experiments, unilateral efferent duct ligation was performed in male rats before treatment with sulphapyridine $(321 \mathrm{mg} / \mathrm{kg} /$ day). After 7 days of treatment, the rats were anaesthetized with pentobarbitone sodium $(60 \mathrm{mg} / \mathrm{kg})$ and blood sera and epididymal fluids were collected for the determination of sulphapyridine concentrations.

Determination of drug concentrations in blood and epididymal plasmas. The concentrations of sulphapyridine, sulphamerazine, dapsone, sulphamethoxazole, sulphamethizole and trimethoprim in blood sera and epididymal fluids were measured by high performance liquid chromatography (HPLC) (Fischer \& Klotz, 1978) using an apparatus (Waters Associates, Model 440: Milford, MA, U.S.A.) equipped with an automatic gradient controller, a u.v. detector set at $254 \mathrm{~nm}$ and a reversed-phase column ( $\mu$ Bondapak C18, $3.9 \mathrm{~mm} \times 30 \mathrm{~cm})$.

Blood sera and epididymal plasmas were filtered through a micropartition system fitted with a YMT filtration membrane (Amicon Danvers, MA, U.S.A.) to separate the free (unbound) drugs from the bound (to proteins) drugs. To the filtrates so obtained $(\sim 50 \mu \mathrm{l})$ and the epididymal plasmas $(5-20 \mu \mathrm{l}$ were added $250 \mu \mathrm{l}$ acetate buffer $(1 \mathrm{M}, \mathrm{pH} 4 \cdot 7)$, $10 \mu \mathrm{l}$ internal standards (sulfamethoxazole for sulphapyridine and dapsone assays; dapsone for trimethoprim, sulphamethizole and sulphamerazine assays) and $3 \mathrm{ml}$ solvents (chloroform for dapsone, trimethoprim, sulphamethoxazole, sulphapyridine and sulphamethizole assays; acetone/ether $(1: 2, \mathrm{v} / \mathrm{v})$ for sulphamerazine assay) and agitated for $2 \mathrm{~h}$ and then centrifuged at $3000 \mathrm{~g}$ for $15 \mathrm{~min}$. The separated organic phase was evaporated to complete dryness under reduced pressure and redissolved in $50 \mu \mathrm{l}$ acetonitrile/water $(20 / 80 \mathrm{v} / \mathrm{v})$ and $10 \mu \mathrm{l}$ injected into the HPLC system. The concentrations of drugs in blood sera and epididymal plasmas were quantified by calculating the peak area ratios of the drug to the added internal standard and relating them to a previously constructed calibration curve obtained from sera containing different amounts of the drug (Fischer \& Klotz, 1978). The recoveries of the assays ranged from 60 to $90 \%$. 
The drugs were obtained from Sigma (St Louis, MO, U.S.A.) except for frusemide and tolbutamide which were gifts from the International Organization for Chemical Sciences in Development (IOCD).

Statistical analysis. Differences between treated and control groups were compared by using an analysis of variance. All data are presented as mean \pm s.e.m.

\section{Results}

\section{Effects on fertility and fecundity}

Of the 19 compounds tested, sulphaguanidine, sulphapyridine, dapsone, sulphamethazine, sulphamethoxypyridazine, sulphathiazole, sulphamerazine and sulphadimethoxine reduced the fecundity of male rats by significantly reducing the embryo number over corpus luteum number per pregnant female (Table 2). The numbers of female rats impregnated by the males treated with sulphapyridine, dapsone, sulphamethazine, sulphathiazole and sulphamethoxypyridazine were also reduced (Table 1). If the percentage of pregnant females was taken into account in the expression of the 'Fecundity Index' (see 'Materials and Methods'), then sulphapyridine, dapsone and sulphamethazine reduced fecundity by more than $50 \%$ compared with normal rats. The other 11 compounds tested had no effect on fecundity of male rats (Table 2).

Table 1. Fertility of male rats and the number of pregnancies resulting after oral administration of drugs to male rats

\begin{tabular}{|c|c|c|c|c|c|}
\hline \multirow{2}{*}{$\begin{array}{l}\text { Compounds } \\
\text { administered }\end{array}$} & \multirow{2}{*}{$\begin{array}{c}\text { Dosage* } \\
\text { (mg/kg/day) }\end{array}$} & \multicolumn{2}{|c|}{$\begin{array}{l}\text { Fertile } \\
\text { male rats }\end{array}$} & \multicolumn{2}{|c|}{$\begin{array}{l}\text { Pregnant } \\
\text { female rats }\end{array}$} \\
\hline & & No. & $\%$ & No. & $\%$ \\
\hline Control & & $6 / 6$ & 100 & $11 / 12$ & $91 \cdot 7$ \\
\hline Acetazolamide & $50 \cdot 0$ & $11 / 12$ & $91 \cdot 7$ & $22 / 24$ & $91 \cdot 7$ \\
\hline Frusemide & $2 \cdot 9$ & $12 / 12$ & 100 & $21 / 24$ & 87.5 \\
\hline Sulphapyridine & $321 \cdot 0$ & $4 / 4$ & 100 & $6 / 8$ & $75 \cdot 0$ \\
\hline Control & & $6 / 6$ & 100 & $11 / 11$ & 100 \\
\hline Dapsone & $50 \cdot 0$ & $7 / 7$ & 100 & $11 / 13$ & $84 \cdot 6$ \\
\hline Pyrimethamine & $50 \cdot 0$ & $6 / 6$ & 100 & $11 / 12$ & $91 \cdot 7$ \\
\hline Propranolol & $23 \cdot 0$ & $6 / 6$ & 100 & $11 / 12$ & $91 \cdot 7$ \\
\hline Sulphamerazine & $427 \cdot 0$ & $6 / 6$ & 100 & $12 / 13$ & $92 \cdot 3$ \\
\hline Control & & $9 / 9$ & 100 & $18 / 18$ & 100 \\
\hline Trimethoprim & $100 \cdot 0$ & $7 / 7$ & 100 & $14 / 14$ & 100 \\
\hline Hydrochlorothiazide & $28 \cdot 6$ & $8 / 8$ & 100 & $14 / 16$ & $87 \cdot 5$ \\
\hline Tolbutamide & $285 \cdot 0$ & $7 / 8$ & 87.5 & $12 / 16$ & $75 \cdot 0$ \\
\hline Sulphamethizole & $300 \cdot 0$ & $7 / 8$ & $87 \cdot 5$ & $12 / 16$ & $75 \cdot 0$ \\
\hline Control & & $8 / 8$ & 100 & $15 / 15$ & 100 \\
\hline Sulphamethazine & $1100 \cdot 0$ & $5 / 7$ & $71 \cdot 4$ & $7 / 12$ & $58 \cdot 3$ \\
\hline Sulphathiazole & $700 \cdot 0$ & $8 / 8$ & 100 & $15 / 16$ & 93.8 \\
\hline Sulphamethoxypyridazine & $200 \cdot 0$ & $5 / 6$ & $83 \cdot 3$ & $7 / 11$ & 63.6 \\
\hline Sulphadimethoxine & $285 \cdot 0$ & $8 / 8$ & 100 & $14 / 15$ & $93 \cdot 3$ \\
\hline Control & & $12 / 12$ & 100 & $24 / 36$ & $66 \cdot 7$ \\
\hline Sulphaguanidine & $140 \cdot 0$ & $12 / 12$ & 100 & $26 / 36$ & $83 \cdot 3$ \\
\hline Para-aminohippuric acid & $200 \cdot 0$ & $12 / 12$ & 100 & $30 / 36$ & $83 \cdot 3$ \\
\hline Sulphadiazine & $26 \cdot 7$ & $12 / 12$ & 100 & $27 / 36$ & $75 \cdot 0$ \\
\hline Sulphamethoxazole & $200 \cdot 0$ & $12 / 12$ & 100 & $32 / 36$ & 88.9 \\
\hline
\end{tabular}

*All drugs administered for 6 weeks. 


\section{Effects on sperm concentration and motility}

As shown in Table 3, frusemide, pyrimethamine, sulphapyridine and sulphaguanidine significantly reduced sperm concentration by $9,22,20$ and $17 \%$, respectively. The capacity to initiate forward motility of the cauda epididymal spermatozoa was reduced by dapsone (by $30 \%$ ), propranolol (by $38 \%$ ), sulphamerazine (by $49 \%$ ) and sulphamethoxypyridazine (by $64 \%$ ).

\section{Effect on body weight}

Some of the compounds administered caused a fall in body weight when measured at the end of the dosage period (Table 3). These drugs included sulphamerazine, pyrimethamine and sulphadimethoxine. Of these sulphamerazine and sulphadimethoxine possessed an antifertility effect (Table 2), whereas pyrimethamine was inactive.

\section{Effects on testis and seminal vesicle weights}

Frusemide, pyrimethamine and sulphamethoxypyridazine significantly reduced testis weight by $5 \%, 33 \%$ and $16 \%$, respectively (Table 3). Sulphamerazine and sulphadimethoxine resulted in

Table 2. Fecundity of male rats after oral administration of sulphonamides and other compounds

\begin{tabular}{|c|c|c|c|c|c|c|}
\hline \multirow{2}{*}{$\begin{array}{l}\text { Compound } \\
\text { administered }\end{array}$} & \multirow{2}{*}{$\begin{array}{c}\% \\
\text { Pregnant } \\
\text { females }\end{array}$} & \multirow{2}{*}{$\begin{array}{l}\text { Embryo no. } \\
\text { per pregnant } \\
\text { female }\end{array}$} & \multirow{2}{*}{$\begin{array}{c}\text { Mean Day } 2 \\
\text { embryo length } \\
(\mathrm{mm})\end{array}$} & \multirow{2}{*}{$\begin{array}{c}\text { Embryo no./ } \\
\text { CL no. }\end{array}$} & \multicolumn{2}{|c|}{ 'Fecundity Index' } \\
\hline & & & & & value $(\%$ & of control) \\
\hline Control & 91.7 & $14.0 \pm 0.7$ & $26.7 \pm 0.8$ & $0.88 \pm 0.03$ & $2154 \cdot 6$ & $(100 \cdot 0)$ \\
\hline Acetazolamide & 91.7 & $12 \cdot 7 \pm 0.7$ & $27.6 \pm 0.6$ & $0.87 \pm 0.04$ & $2201 \cdot 9$ & $(102 \cdot 2)$ \\
\hline Frusemide & $87 \cdot 5$ & $13 \cdot 3 \pm 1 \cdot 0$ & $26.8 \pm 0.3$ & $0.85 \pm 0.06$ & $1993 \cdot 3$ & $(92 \cdot 3)$ \\
\hline Sulphapyridine & $75 \cdot 0$ & $5 \cdot 0 \pm 2 \cdot 2^{c}$ & $30.0 \pm 0.5^{2}$ & $0.36 \pm 0.13^{c}$ & $810 \cdot 0$ & $(37 \cdot 6)$ \\
\hline Control & 100 & $13.5 \pm 1.8$ & $22.9 \pm 4.2$ & $0.84 \pm 0.12$ & $1923 \cdot 6$ & $(100 \cdot 0)$ \\
\hline Dapsone & 84.6 & $6 \cdot 0 \pm 1.4^{c}$ & $22.9 \pm 6.6$ & $0 \cdot 38 \pm 0 \cdot 10^{c}$ & $736 \cdot 2$ & $(38 \cdot 3)$ \\
\hline Pyrimethamine & $91 \cdot 7$ & $12.9 \pm 1.8$ & $21 \cdot 7 \pm 4.5$ & $0.83 \pm 0.11$ & $1651 \cdot 6$ & $(85 \cdot 9)$ \\
\hline Propranolol & 91.7 & $14 \cdot 5 \pm 2 \cdot 0$ & $21.6 \pm 6.4$ & $0.92 \pm 0.13$ & $1822 \cdot 3$ & $(94 \cdot 7)$ \\
\hline Sulphamerazine & $92 \cdot 3$ & $11 \cdot 7 \pm 1 \cdot 5$ & $21 \cdot 7 \pm 6.5$ & $0.72 \pm 0.09^{\mathrm{a}}$ & $1442 \cdot 1$ & $(75 \cdot 0)$ \\
\hline Control & 100 & $11.6 \pm 0.8$ & $22.7 \pm 0.3$ & $0.78 \pm 0.05$ & $1770 \cdot 6$ & $(100 \cdot 0)$ \\
\hline Trimethoprim & 100 & $14.0 \pm 0.7$ & $22.4 \pm 0.3$ & $0.81 \pm 0.05$ & $1814 \cdot 4$ & $(102 \cdot 5)$ \\
\hline Hydrochlorothiazide & $87 \cdot 5$ & $13.8 \pm 0.7$ & $23.5 \pm 0.6$ & $0.90 \pm 0.03$ & $1850 \cdot 6$ & $(104 \cdot 5)$ \\
\hline Tolbutamide & $75 \cdot 0$ & $13 \cdot 1 \pm 0.8$ & $22 \cdot 7 \pm 0.4$ & $0.84 \pm 0.04$ & $1430 \cdot 1$ & $(80.8)$ \\
\hline Sulphamethizole & $75 \cdot 0$ & $13 \cdot 3 \pm 0 \cdot 7$ & $23 \cdot 0 \pm 0 \cdot 1$ & $0.87 \pm 0.03$ & $1500 \cdot 8$ & $(84 \cdot 8)$ \\
\hline Control & 100 & $14.2 \pm 0.8$ & $22 \cdot 1 \pm 0 \cdot 3$ & $0.89 \pm 0.04$ & $1966 \cdot 9$ & $(100 \cdot 0)$ \\
\hline Sulphamethazine & $58 \cdot 3$ & $7 \cdot 4 \pm 1 \cdot 6^{\mathrm{b}}$ & $21.8 \pm 0.5$ & $0.53 \pm 0.11^{b}$ & 673.9 & $(34 \cdot 3)$ \\
\hline Sulphathiazole & $93 \cdot 8$ & $8 \cdot 3 \pm 1 \cdot 4^{b}$ & $23 \cdot 4 \pm 0.4^{a}$ & $0.52 \pm 0.09^{b}$ & $1140 \cdot 8$ & $(58 \cdot 0)$ \\
\hline Sulphamethoxypyridazine & $63 \cdot 6$ & $9 \cdot 4 \pm 2 \cdot 1^{\mathrm{a}}$ & $24 \cdot 1 \pm 8 \cdot 5$ & $0.57 \pm 0.19^{a}$ & 1054.9 & $(53.6)$ \\
\hline Sulphadimethoxine & $93 \cdot 3$ & $10 \cdot 0 \pm 1 \cdot 1^{b}$ & $22.7 \pm 0.3$ & $0.65 \pm 0.07^{b}$ & $1546 \cdot 6$ & $(78 \cdot 6)$ \\
\hline Control & $66 \cdot 7$ & $11.8 \pm 0.8$ & $23.4 \pm 1.6$ & - & $279 \pm 26 \cdot 0^{*}$ & $(100 \cdot 0)$ \\
\hline Sulphaguanidine & $83 \cdot 3$ & $7 \cdot 3 \pm 1 \cdot 4^{b}$ & $21 \cdot 8 \pm 4.3$ & - & $155 \pm 30 \cdot 4^{\mathrm{b*}}$ & $(55 \cdot 6)$ \\
\hline Para-aminohippuric acid & $83 \cdot 3$ & $12 \cdot 8 \pm 2 \cdot 3$ & $16 \cdot 8 \pm 3 \cdot 1$ & - & $212 \pm 38 \cdot 6^{*}$ & $(76 \cdot 0)$ \\
\hline Sulphadiazine & $75 \cdot 0$ & $13.2 \pm 0.5$ & - & - & - & - \\
\hline Sulphamethoxazole & 88.9 & $12 \cdot 5 \pm 2 \cdot 2$ & $17.9 \pm 1.4$ & - & $218 \pm 38 \cdot 6^{*}$ & $(78 \cdot 1)$ \\
\hline
\end{tabular}

Values are the mean \pm s.e.m. $(n=6-32)$.

*Expressed as 'Embryo Score' (see text).

Values significantly different from control: a, $P<0.05$; b, $P<0.01$; c, $P<0.001$. 
Table 3. Effects of sulphonamides and other drugs on sperm concentration and viability of epididymal spermatozoa, and on body and testis weight

\begin{tabular}{|c|c|c|c|c|c|}
\hline $\begin{array}{l}\text { Compound } \\
\text { administered }\end{array}$ & $\begin{array}{l}\text { No. of } \\
\text { animals }\end{array}$ & $\begin{array}{l}\text { Sperm conc. } \\
\left(\times 10^{-9} / \mathrm{ml}\right)\end{array}$ & $\begin{array}{c}\text { 'Forward Motility } \\
\text { Index' }\end{array}$ & $\begin{array}{c}\text { Body } \\
\text { weight }(\mathrm{g})\end{array}$ & $\begin{array}{c}\text { Testis wt } \\
(\mathrm{g} / 100 \mathrm{~g} \text { body } w \mathrm{t})\end{array}$ \\
\hline Control & 6 & $2 \cdot 14 \pm 0 \cdot 19$ & $2754.6 \pm 266.8$ & $428 \cdot 5 \pm 12 \cdot 2$ & $0.378 \pm 0.010$ \\
\hline Acetazolamide & 12 & $2 \cdot 04 \pm 0 \cdot 10$ & $2670 \cdot 6 \pm 269 \cdot 2$ & $438.3 \pm 6.8$ & $0.373 \pm 0.007$ \\
\hline Frusemide & 12 & $1.95 \pm 0.06^{\mathrm{a}}$ & $2850.3 \pm 245.6$ & $446.4 \pm 8.9$ & $0.358 \pm 0.006^{\mathrm{a}}$ \\
\hline Sulphapyridine & 4 & $1 \cdot 71 \pm 0.20^{\mathrm{a}}$ & $2583 \cdot 3 \pm 392 \cdot 1$ & $465 \cdot 0 \pm 12 \cdot 7$ & $0.364 \pm 0.012$ \\
\hline Control & 10 & $2 \cdot 30 \pm 0.10$ & $2391 \cdot 6 \pm 228 \cdot 7$ & $450.0 \pm 9.4$ & $0.369 \pm 0.018$ \\
\hline Dapsone & 8 & $2 \cdot 10 \pm 0 \cdot 10$ & $1667 \cdot 5 \pm 216 \cdot 5^{a}$ & $431.5 \pm 9.2$ & $0.401 \pm 0.016$ \\
\hline Pyrimethamine & 6 & $1.80 \pm 0.20^{\mathrm{a}}$ & $2014 \cdot 7 \pm 265 \cdot 0$ & $409 \cdot 3 \pm 5 \cdot 6^{b}$ & $0.249 \pm 0.017^{\mathfrak{c}}$ \\
\hline Propranolol & 7 & $2 \cdot 10 \pm 0 \cdot 10$ & $1478 \cdot 5 \pm 226.7^{b}$ & $422 \cdot 0 \pm 11.4$ & $0.383 \pm 0.011$ \\
\hline Sulphamerazine & 7 & $2 \cdot 3 \pm 0.10$ & $1437 \cdot 3 \pm 253 \cdot 6^{b}$ & $374 \cdot 3 \pm 16 \cdot 1^{c}$ & $0.442 \pm 0.013^{b}$ \\
\hline Control & 9 & $1.96 \pm 0.09$ & $2212 \cdot 0 \pm 244 \cdot 0$ & $437.0 \pm 10.4$ & $0.380 \pm 0.010$ \\
\hline Trimethoprim & 7 & $1.83 \pm 0.70$ & $2900 \cdot 3 \pm 208 \cdot 8$ & $438.6 \pm 5.4$ & $0.372 \pm 0.011$ \\
\hline Hydrochlorothiazide & 8 & $1.78 \pm 0.15$ & $2312 \cdot 3 \pm 102 \cdot 8$ & $414.6 \pm 13.8$ & $0.361 \pm 0.034$ \\
\hline Tolbutamide & 8 & $1.79 \pm 0.13$ & $2546.2 \pm 677.3$ & $436.9 \pm 6.9$ & $0.355 \pm 0.019$ \\
\hline Sulphamethizole & 8 & $1.82 \pm 0.07$ & $1967 \cdot 0 \pm 551 \cdot 7$ & $434 \cdot 3 \pm 8 \cdot 3$ & $0.359 \pm 0.016$ \\
\hline Control & 8 & $1.93 \pm 0.12$ & $1707 \cdot 4 \pm 267 \cdot 3$ & $428 \cdot 0 \pm 11 \cdot 0$ & $0.375 \pm 0.015$ \\
\hline Sulphamethazine & 7 & $1.76 \pm 0.02$ & $1824.3 \pm 482.2$ & $394.0 \pm 20.0$ & $0.390 \pm 0.018$ \\
\hline Sulphathiazole & 8 & $1.81 \pm 0.08$ & $1584.4 \pm 264.5$ & $435.0 \pm 7.0$ & $0.368 \pm 0.011$ \\
\hline Sulphamethoxypyridazine & 6 & $1.95 \pm 0.14$ & $618 \cdot 0 \pm 170 \cdot 2^{b}$ & $432.5 \pm 15.6$ & $0.316 \pm 0.013^{a}$ \\
\hline Sulphadimethoxine & 8 & $1.93 \pm 0.09$ & $1808.9 \pm 619.9$ & $307 \cdot 0 \pm 6 \cdot 0^{\mathrm{c}}$ & $0.495 \pm 0.015^{c}$ \\
\hline Control & 18 & $1.63 \pm 0.06$ & Normal† & $459.4 \pm 8.0$ & $0.365 \pm 0.011$ \\
\hline Sulphaguanidine & 12 & $1 \cdot 36 \pm 0.09^{a}$ & Normal & $440.8 \pm 13.8$ & $0.382 \pm 0.021$ \\
\hline Para-aminohippuric acid & 12 & $1.82 \pm 0.16(11)$ & Normal (11) & $471.6 \pm 14.9$ & $0.363 \pm 0.011$ \\
\hline Sulphadiazine & 12 & $1.64 \pm 0.14$ & Normal & $442.5 \pm 5.9$ & $0.377 \pm 0.009$ \\
\hline Sulphamethoxazole & 12 & $1.81 \pm 0.09$ & Normal & $454.0 \pm 10 \cdot 6$ & $0.371 \pm 0.014$ \\
\hline
\end{tabular}

Values are the mean \pm s.e.m.

†Direct visual assessment.

Values significantly different from control: a, $P<0.05$; b, $P<0.01$; c, $P<0.001$.

significantly greater relative testis weight (Table 3) and epididymal weight (data not shown). These effects may be related to the reduction in body weight seen after treatment with these two sulphonamides. None of the test compounds studied reduced epididymal weight and seminal vesicle weight.

\section{Accumulation of drugs in the epididymis}

The concentrations of sulphapyridine, sulphamethoxazole, dapsone, sulphamerazine, trimethoprim and sulphamethizole in blood and in epididymal plasma were measured by HPLC. The peaks in the chromatograms were identified as the various test compounds when checked against the retention times of the corresponding standards (Fig. 1). The concentrations of these compounds in blood sera and epididymal plasmas were calculated from the chromatograms (see 'Methods') and are given in Table 4. The concentrations of dapsone and sulphamethizole in epididymal plasmas approached those in blood sera after 6 weeks treatment with the drugs. Sulphapyridine, sulphamerazine and sulphamethoxazole accumulated in the epididymis at concentrations about 2-4 times higher than the free drug concentrations in blood sera. The concentration of trimethoprim in the epididymal plasma was significantly lower than that in blood serum.

In some experiments, unilateral efferent duct ligation was performed in male rats before treatment with sulphapyridine $(321 \mathrm{mg} / \mathrm{kg} /$ day). After treatment for 7 days, blood serum and epididymal 


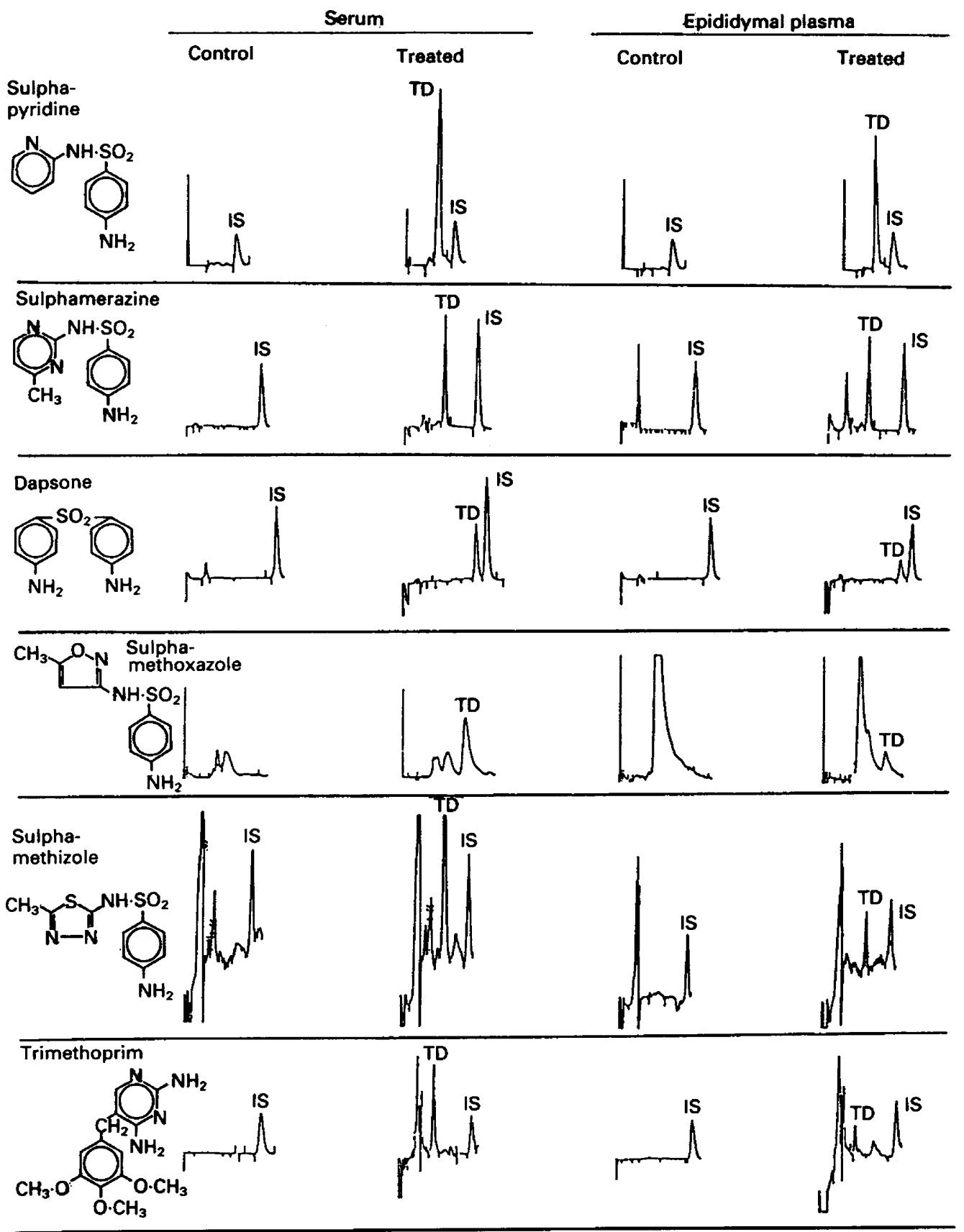

Fig. 1. Typical HPLC chromatograms of blood serum and epididymal plasma samples from control and drug-treated rats. IS $=$ internal standard; TD $=$ test drug. 
Table 4. Drug concentrations in serum and epididymal plasma samples of treated rats

\begin{tabular}{|c|c|c|c|}
\hline \multirow[b]{2}{*}{ Drug } & \multirow{2}{*}{$\begin{array}{l}\% \text { 'Fecundity } \\
\text { Index' of control }\end{array}$} & \multicolumn{2}{|c|}{ Drug conc. $(\mu \mathrm{g} / \mathrm{ml})$} \\
\hline & & Serum & Epididymal plasma \\
\hline Sulphapyridine & 37.6 & $96.7 \pm 11.6(6)$ & ${ }^{b} 192 \cdot 3 \pm 17 \cdot 1(6)$ \\
\hline Sulphamerazine & 75.0 & $16.8 \pm 1.3(7)$ & $72.9 \pm 7.6(7)$ \\
\hline Dapsone & $38 \cdot 3$ & $1.9 \pm 0.3(8)$ & $2.9 \pm 1.2(7)$ \\
\hline Sulphamethoxazole & —* & $2.4 \pm 1.0(6)$ & $11.4 \pm 3.8(6)$ \\
\hline Sulphamethizole & —* & $1.3 \pm 0.3(7)$ & $1.4 \pm 0.4(7)$ \\
\hline Trimethoprim & -* & $3.6 \pm 0.9(7)$ & ${ }^{\mathrm{a}} 0.7 \pm 0.4(6)$ \\
\hline
\end{tabular}

Values are mean \pm s.e.m. with no. of determinations shown in parentheses.

*No significant antifertility effect.

Value significantly different from serum concentration: $a, P<0.01 ; b, P<0.001$.

plasma samples were collected and the sulphapyridine concentration determined. The mean \pm s.e.m. concentration of free sulphapyridine in blood serum was $42.05 \pm 13.47 \mu \mathrm{g} / \mathrm{ml}(n=5)$ and those of the ipsilateral ligated epididymis and the contralateral unligated epididymis were $45 \cdot 88 \pm 13.39$ $(n=5)$ and $38.96 \pm 10.61(n=5) \mu \mathrm{g} / \mathrm{ml}$, respectively (not statistically significantly different).

\section{Discussion}

This paper describes the screening of 19 compounds for their antifertility effects in male rats. This work stemmed from the observation that men taking sulphasalazine for ulcerative colitis and Crohn's disease become infertile (for references, see 'Introduction'). Earlier reports in the literature have associated sulphonamide treatments with male infertility (Walker, 1944; Minguet, 1947). Cotrimoxazole, a sulphonamide-containing mixture, and dapsone, a sulphonamide-related molecule, were also found to impair semen quality (Murdia et al., 1978). To date, nothing is known about the basis of the antifertility effects of these compounds.

The 19 compounds tested represent a diverse group of drugs which are commonly used for their antimicrobial, antibacterial, hypoglycaemic, diuretic and antihypertensive effects. Some of the sulphonamides are structurally related to sulphapyridine which has been shown to possess an antifertility effect in male rats (Levi et al., 1982; Pholpramool \& Srikhao, 1983; O'Morain et al., 1985). Of these 19 compounds, sulphapyridine, sulphaguanidine, sulphamerazine, sulphamethazine, sulphathizole, sulphamethoxypyridazine, sulphadimethoxine and dapsone reduced the fecundity of male rats to $37 \cdot 6,55 \cdot 6,75,34 \cdot 3,58,53 \cdot 6,78 \cdot 6$ and $38 \cdot 3 \%$ of control, respectively (Table 2 ). Our results are consistent with previous findings that sulphapyridine reduced fecundity of male rats by reducing the number of live fetuses in each pregnant female but had no effect on epididymal sperm motility (O’Morain et al., 1985).

The present data do not allow us to identify the site of action of the 8 compounds that had an antifertility effect. They could act by inhibiting gonadotrophin secretion, by suppressing spermatogenesis, or by interfering with sperm maturation and storage. Cosentino et al. (1984) and Chodorge et al. (1986) found that sulphasalazine treatment did not alter the plasma concentrations of FSH, LH, prolactin and testosterone. Pholpramool \& Srikhao (1983) also observed no change in serum testosterone after sulphapyridine treatment in male rats. It is unlikely that the adverse effects of the 8 compounds on fecundity in this study were mediated through an effect on the pituitary hormonal feedback system, although hormone levels were not determined. Likewise, our present data cannot discriminate between a testicular action or an epididymal one and it is possible that the drugs might have acted on both. Testis weight or sperm concentration in the epididymis was reduced after treatment with sulphamethoxypyridazine, sulphapyridine and sulphaguanidine. However, these 
values were not altered by the other active compounds. If the lesion at the testis is at the late stage of spermatogenesis, as has been suggested for sulphasalazine and sulphapyridine (Levi et al., 1982), then there would not be a significant reduction in sperm concentration in the epididymis.

The mechanisms that are responsible for the antifertility effect of the 8 active compounds are unknown. Epididymal sperm motility was lower than normal after dapsone, sulphamerazine and sulphamethoxypyridazine treatment. However, a decrease in sperm motility cannot fully account for the antifertility effects of all the active compounds: propranolol which significantly decreased motility to the same extent (Tables $2 \& 3$ ) had no effect on fertility. Sperm motility was apparently normal after sulphapyridine, sulphamethazine, sulphathizole and sulphaguanidine treatment despite a fall in fecundity in the male rats treated with these compounds (Table 3 ).

The epididymis has been shown to secrete para-aminohippurate (PAH) from blood into lumen by a probenecid-sensitive pathway (Qiu \& Wong, 1985). Since PAH is the prototype of drugs which are actively secreted by the renal tubular cells, it is likely that the epididymis also secretes other organic acids by the same pathway. To test whether some of these compounds are secreted by the epididymal cells, we measured the accumulation of 6 of them in the epididymal fluid (Fig. 1). The concentrations of dapsone and sulphamethizole in the epididymal fluid approached those in blood, whereas sulphapyridine, sulphamerazine and sulphamethoxazole were actively secreted by the epididymis, i.e. there was a lumen to blood concentration gradient. The accumulation of sulphapyridine was not affected by efferent duct ligation, indicating that the drug was not simply brought down from the testis in the testicular fluid, but was transported into the lumen through the bloodepididymis barrier. Sulphamerazine, sulphapyridine and dapsone were effective in reducing fecundity while sulphamethoxazole was not. Trimethoprim, a drug that did not affect fertility, was not present in the epididymal fluid at a significant level. The concentration achieved in the epididymal fluid was much lower than in blood (Table 4).

It seems that the blood-epididymis barrier can discriminate amongst various drug molecules with regard to their permeation into the epididymal lumen. The three sulphonamides, although sulphapyridine, sulphamerazine and sulphamethoxazole all penetrated into the epididymis, only sulphapyridine and sulphamerazine were effective in reducing fecundity. Although there is no direct relationship between the antifertility efficacy and the degree of accumulation in the epididymis (epididymal fluid concentration over blood concentration), there is some indication that their presence in the epididymis is a prerequisite for an antifertility effect. Trimethoprim which permeated the blood-epididymis barrier poorly was inactive (Table 5).

We therefore suggest that the presence of drug molecules in the epididymis was at least partly responsible for the antifertility action of sulphapyridine, sulphamerazine and dapsone. After access into the epididymal compartment, the drugs could bind to sperm membranes and affect capacitation, the acrosome reaction, or any post-testicular event that is essential for the successful penetration of the oocyte. Spermatozoa of animals and men treated with sulphasalazine or sulphapyridine display larger heads or 'megalo' head forms which may reflect a direct damaging effect of the drugs on the sperm acrosomal membrane (Toth, 1979; Hudson et al., 1982).

Spermatozoa from hamsters fed with sulphasalazine have normal metabolism and motility, and yet are unable to undergo the acrosome reaction or penetrate hamster eggs in vitro ( $\mathrm{O}^{\prime} \mathrm{Morain}$ et al., 1985). Chodorge et al., (1986) reported that sulphasalazine did not alter the composition of the epididymal 'milieu' and hence epididymal functions. The lesion produced by sulphasalazine seems to reside on the sperm membrane; an increase in sperm membrane lipid peroxidation after sulphasalazine treatment has been described (see Chodorge et al., 1986). These observations are in accord with a direct effect on epididymal spermatozoa of sulphasalazine or its metabolite, sulphapyridine which enters the epididymis through transport across the blood-epididymis barrier.

This work was supported by the World Health Organization, Special Programme for Research, Development and Research Training in Human Reproduction (Project 85009) and the University of Hong Kong. 


\section{References}

Chodorge, F., Dupont, C., Lataillade, G., Kercret, H., Jegou, B. \& Soufir, J.C. (1986) Sulphasalazine: Possible mechanism of induced infertility in the male rat. Proc. 4th Eur. Workshop on Molecular and Cellular Endocrinology of the Testis, Capri, G 1, Abstr.

Cosentino, M.J., Chey, W.Y., Takihara, H. \& Cockett, A.T.K. (1984) The effects of sulfsalazine on human male fertility potential and seminal prostaglandins. $J$. Urol. 132, 682-686.

Dissanayake, A.S. \& Truelove, S.C. (1973) A controlled therapeutic trial of long-term maintenance treatment of ulcerative colitis with sulphasalazine (Salazopyrine). Gut 14, 923-926.

Fischer, C. \& Klotz, U. (1978) Determination of sulfapyridine and its major metabolites in plasma by highpressure liquid chromatography. J. Chromatogr. 146, 157-162.

Hudson, E., Dore, C., Sowter, C., Toovey, S. \& Levi, A.J. (1982) Sperm size in patients with inflammatory bowel disease on sulphasalazine therapy. Fert. Steril. 38, 77-84.

Levi, A.J., Fisher, A.M., Hughes, L. \& Hendry, W.F. (1979) Male infertility due to sulphasalazine. Lancet 2, 276-278.

Levi, A.J., Smethurst, P. \& O'Morain, C.A. (1982) Sulphasalazine-induced male infertility in man and rats. Archs Androl. 9, 18-19.

Minguet (1947) Sulphonamides provoke azospermia. $J$. Am. vet. Med. Ass. 110, 39.

Murdia, A., Mathur, V., Kothari, L.K. \& Singh, K.P. (1978) Sulphatrimethoprim combinations and male infertility. Lancet 2, 276.

O'Morain, C., Smethurst, P. \& Dore, C.J. (1984) Reversible male infertility due to sulphasalazine: Studies in man and rat. Gut 25, 1078-1084.
O'Morain, C., Smethurst, P. \& Levi, A.J. (1985) Reversible male infertility induced by sulphasalazine. In Male Fertility and its Regulation, pp. 49-54. Eds T. J. Lobl \& E. S. E. Hafez. MTP Press, Lancaster.

Peppercorn, M.A. \& Goldman, P. (1972) The role of intestinal bacteria in the metabolism of salicylazosulfapyridine. J. Pharm. exp. Ther. 181, 555-561.

Pholpramool, C. \& Srikhao, A. (1983) Antifertility effect of sulfasalazine in the male rat. Contraception 28, 273-279.

Qiu, J.P. \& Wong, P.Y.D. (1985) Secretion of paminohippurate by the rat epididymis. J. Physiol., Lond. 364, 241-248.

Svartz, N. (1942) Salazopyrin, a new sulfanilamide preparation. Acta med. scand. 110, 577-598.

Toovey, S., Hudson, E., Hendry, W.F. \& Levi, A.J. (1981) Sulphasalazine and male infertility: reversibility and possible mechanism. Gut 22, 445-451.

Toth, A. (1979) Reversible toxic effect of salicylazosulfapyridine on semen quality. Fert. Steril. 31, 538-540.

Walker, K. (1944) Sulphonamides and infertility. Lancet 2, 192.

Wong, P.Y.D. \& Lee, W.M. (1982) Effect of spironolactone (aldosterone antagonist) on electrolyte and water content of the cauda epididymidis and fertility of male rats. Biol. Reprod. 27, 771-777.

Wong, P.Y.D., Lee, W.M. \& Tsang, A.Y.F. (1981) The effects of extracellular sodium ions on acid release and motility in rat caudal epididymal spermatozoa in vitro. Expl Cell Res. 131, 97-104.

Received 4 March 1987 